\title{
Dawn of Modern Wheat Genetics: The Story of the Wheat Stocks That Contributed to the Early Stage of Wheat Cytogenetics
}

\author{
Koichiro Tsunewaki*† \\ Faculty of Agriculture, Kyoto University, Sakyo-ku, Kyoto 606-8501, Japan
}

Received July 9, 2018; accepted August 3, 2018

\begin{abstract}
Summary This story began in October, 1913, with a letter from Konstantin Flaksberger, Bureau of Applied Botany, Russia, wrote to Yuzo Hoshino, Hokkaido University, Japan, requesting seeds of Japanese cereals. Handed his letter by Hoshino, Takajiro Minami, Director of the University's Experimental Farm, responded by sending Flaksberger seeds of oats and barley in December, 1913, and of barley and wheat in September, 1915. Minami then asked Flaksberger for Russian wheat and other cereals, and acknowledged their receipt in May, 1916, after which their correspondence ceased. Tetsu Sakamura had been a graduate student in the Faculty of Agriculture, Hokkaido University since 1913, carrying out chromosome studies of leguminous species, but he switched to wheat in 1916, asking Minami to provide wheat seeds. Using material that originated from Flaksberger, Sakamura determined the correct chromosome numbers of eight wheat species, among which he discovered polyploidy of $2 n=14(2 x), 28(4 x)$, and 42(6x); these results were published in July, 1918, and in December he left to study overseas for two years. When Hitoshi Kihara entered the graduate course of Hokkaido University in August, 1918, he received Sakamura's materials and started genome analytical work, demonstrating that the set of seven chromosomes of common wheat, which did not exist in tetraploid wheat, was the unit in chromosome transmission as well as in fertilization, thus proposing the concept of the genome. He extended genome analysis to most species of the Triticum-Aegilops complex, determining their genome constitution. His interest then turned to interaction between the nucleus and cytoplasm, and he found that the cytoplasm of Ae. caudata caused male sterility, leading to the discovery of cytoplasmic male sterility in wheat. In 1973, Tsunewaki's group in Kyoto University started an investigation on differentiation of plasmon in the Triticum-Aegilops complex; plasmons of this complex were introduced into 12 wheat genotypes, including three of Flaksberger's stocks, as a result of which 552 alloplasmic lines were produced; their phenotypes and restriction fragment patterns of organellar DNAs were compared. Combining the results of their plasmon analysis and Kihara's genome analysis, the maternal and paternal lineages of most species in this complex were finally determined.
\end{abstract}

Key words Wheat phylogeny, Polyploidy, Genome analysis, Cytoplasmic male sterility, Plasmon analysis, Maternal lineage.

This article is based on the text of a talk given by the author in an international genetics symposium entitled "Celebrating the 100th anniversary of the discovery of correct wheat chromosome numbers and polyploidy by Prof. Tetsu Sakamura", which was organized by the Genetics Society of Japan as part of its 89th Annual Meeting held at Okayama University, Japan in August, 2017.

Here, I will describe the story of wheat genetic stocks that left St. Petersburg, Russia, sometime in October, 1915, passed through $9300 \mathrm{~km}$ of the Siberian Railway during World War I, and reached Sapporo, Japan, sometime before May 19, 1916, where they were utilized in

\footnotetext{
* Corresponding author, e-mail: kkcqn857@yahoo.co.jp

† Present addres: 6-14-10 Kasugadai, Nishi-ku, Kobe 651-2276, Japan DOI: $10.1508 /$ cytologia. 83.351
}

the work of Prof. Tetsu Sakamura to determine the correct chromosome number of wheat species, leading to the discovery of polyploidy in the wheat genus Triticum. Taking over Sakamura's materials, Dr. Hitoshi Kihara established the concept of the genome, and completed genome analysis of two related genera, Triticum and Aegilops; subsequently, my group developed plasmon analysis as the counterpart of Kihara's genome analysis, thus clarifying the maternal and paternal lineages of the two genera.

Four wheat researchers played the major roles in this story: in chronological order of their contribution, these were Dr. Konstantin A. Flaksberger, Dr. Takajiro Minami, Dr. Tetsu Sakamura and Dr. Hitoshi Kihara. 

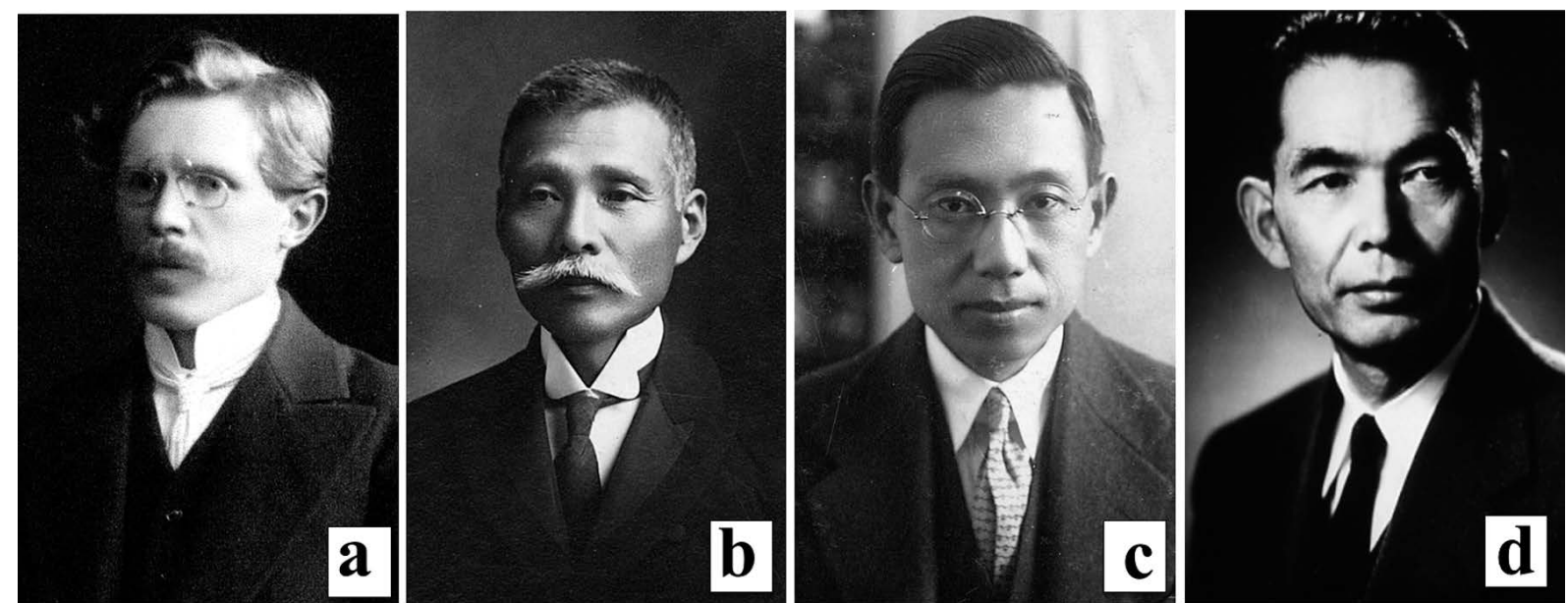

Fig. 1. Photographs of the four scientists who played key roles in this story. a) Dr. Konstantin A. Flaksberger (1880-1942), from Goncharov (2013). b) Dr. Takajiro Minami (1859-1936), provided by the Archives Section of the University Library, Hokkaido University. c) Dr. Tetsu Sakamura (1888-1980), from "Memoir of Prof. Tetsu Sakamura" (Toriyama 1982). d) Dr. Hitoshi Kihara (1893-1986), with permission of Ms. Y. Kihara.

Table 1. Brief biography of Dr. K. A. Flaksberger, from Goncharov (2013).

\begin{tabular}{|c|c|}
\hline Date & Event \\
\hline Aug., 1880 & Born in Grodno, Belarus \\
\hline 1907 & $\begin{array}{l}\text { Graduated from Physics and Mathematics Dept., Yuriev University, Russia, Vice-Director, Bureau of Applied Botany, } \\
\text { Ministry of Agriculture, Russia }\end{array}$ \\
\hline 1915, 1922, 1928, 1939 & Editor of "Wheat Taxonomy" \\
\hline 1929 & Organized All Union Institute of Applied Botany (present Vavilov Institute of Plant Industry) \\
\hline 1937 & Head, Department of Genetics, Plant Breeding \& Seed Production, Leningrad Agricultural Institute \\
\hline June 28, 1941 & Arrested and later transported to Zlatoust Prison, Urals, Russia \\
\hline Sept. 13, 1942 & Died at the age of 62, in Zlatoust Prison Hospital, Urals, Russia \\
\hline
\end{tabular}

Dr. Konstantin Flaksberger (1880-1942),

Bureau of Applied Botany, Russia, working on the phylogeny of the wheat genus Triticum

His photograph and brief biography are given in Fig. 1a and Table 1, respectively, and are both extracted from N. Goncharov's article, published in 2013.

When he graduated in 1907 from the Department of Physics and Mathematics, Imperial Yuriev University, Russia, Flaksberger was immediately appointed ViceDirector of the Bureau of Applied Botany, Ministry of Agriculture, Russia, where he worked throughout his life on the agrobotanical study of wheat. He published four editions of "Wheat Taxonomy" in 1915, 1922, 1928 and 1939. He was arrested on June 28, 1941, about one year after N. I. Vavilov's arrest, and sadly died on September 13, 1942 in Zlatoust Prison Hospital in the Ural District, at the age of 62 .

Figure 2 shows a scheme of wheat genesis according to his investigation, published in 1915, in which he listed 10 Triticum species, classifying them into three conspecies; one of these is conspecies monococcum, in which he placed two species, T. aegilopoides and T. monococcum. In the second conspecies, eu-dicoccoides, four species, T. dicoccoides, T. dicoccum, T. durum and T. polonicum, were placed in this order; and in the last con- species, speltoides, three species, T. spelta, T. vulgare and $T$. compactum, were listed in this order. I will return later to this scheme (Fig. 2), to compare it with the species studied by Sakamura.

When Dr. Jun Hanzawa of Hokkaido University, Sapporo, Japan, visited the Bureau of Applied Botany, sometime between October 3 and 19, 1913, Flaksberger asked him to recommend anyone in Japan with whom he should make contact to get seeds of Japanese crops. Hanzawa suggested his colleague, Dr. Yuzo Hoshino, in Hokkaido University.

Flaksberger wrote a letter to Hoshino, on October 23, 1913, expressing his wish to obtain some seeds of Japanese cultivars of wheat, barley and oats. In this letter, Flaksberger mentioned that the Bulletin of the Bureau of Applied Botany would be sent to whoever supplied the requested seeds to Flaksberger, and this was realized when the Bulletin was sent to Dr. Takajiro Minami in Hokkaido University.

When Hoshino received Flaksberger's letter, he handed it to Minami, then director of the University Farm, asking him to respond to Flaksberger's request. 


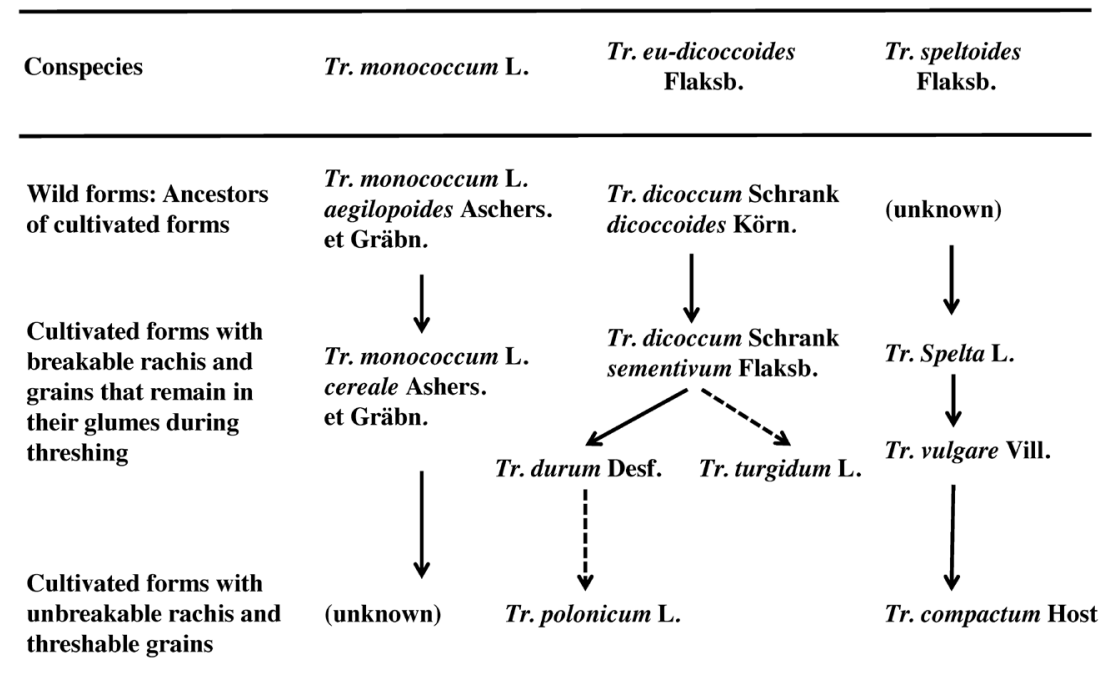

Fig. 2. Scheme of wheat genesis according to the investigation of Flaksberger (1915). Disputable genetic relationships are omitted, except for T. turgidum and T. polonicum (dashed arrows).

Table 2. Brief biography of Dr. T. Minami ${ }^{1)}$.

\begin{tabular}{|c|c|}
\hline Date & Event \\
\hline March, 1859 & Born in Nagasaki prefecture \\
\hline 1877 & Entered Sapporo Agricultural College as a second-term student \\
\hline July, 1881 & $\begin{array}{l}\text { Graduated from Sapporo Agricultural College; appointed as a member of the Land Development Bureau, Ministry of Agricul- } \\
\text { ture, Japan }\end{array}$ \\
\hline 1889 & Professor, Sapporo Agricultural College \\
\hline 1899 & Doctor of Agriculture \\
\hline 1900 & Director, Experimental Farm, Sapporo Agricultural College \\
\hline $1918-1927$ & Professor and Dean, College of Agriculture, Hokkaido University \\
\hline $1930-1933$ & Second President, Hokkaido University \\
\hline August, 1936 & Died at the age of 78 \\
\hline
\end{tabular}

1) Refer to Minami's curriculum vitae as a staff member of Hokkaido University, provided by the Archives Section, Main Library, Hokkaido University, Sapporo, Japan.

Dr. Takajiro Minami (1859-1936),

Director of the University Farm, Hokkaido University, collecting germplasm of crops

Before going further, I will explain the organizational change of Hokkaido University. The university was initially Sapporo Agricultural College, which was established in 1876, and became the College of Agriculture, Tohoku Imperial University in 1907. It then became the independent College of Agriculture, Hokkaido Imperial University in 1918, and finally the present College of Agriculture, Hokkaido University after World War II. For convenience, I will call it "the College of Agriculture, Hokkaido University” after 1907.

Dr. Minami's role in this story is apparent from Sakamura's remarks in his 1918 article, in which he wrote: "I would like to acknowledge Prof. T. Minami and Asst. M. Ito, Agricultural Institute of our University, for their kindness in providing all the materials."

Minami's photograph and brief biography, respectively, are given in Fig. $1 \mathrm{~b}$ and Table 2, all of which information was obtained from the Archives Section of the
University Library, Hokkaido University.

Minami entered Sapporo Agricultural College in 1877 as a second-term student. He was appointed Director of the Experimental Farm of this college in 1900. In 1918, he was promoted to the first Dean of the College of Agriculture, Hokkaido University, and then became the second President of this university in 1930.

Receiving Flaksberger's letter through Hoshino, Minami responded immediately to his request, sending seeds of three oat and eight barley cultivars on December 27, 1913, which were available at that time. Minami sent Flaksberger an additional six barley and four wheat cultivars on September 16, 1915, which he grew in Honshu, the main island of Japan. One month later, on October 7, 1915, Minami wrote another letter to Flaksberger, requesting some seed samples of naked barley, wheat, oats and sunflower, which were grown in Russia, and sent the acknowledgment of receiving 14 seed samples of barley, 18 samples of wheat, three samples of oats and a single sample of sunflower on May 19, 1916; it is evident that Minami received these wheat seeds from Flaksberger sometime between October 7, 1915 and May 19, 1916, 
Table 3. Minami's germplasm collection and distribution of crops during 1913 to 1916.

A. Introduction

\begin{tabular}{rrrrrrrr}
\hline \hline \multirow{2}{*}{ Year } & No. cases & \multicolumn{7}{c}{ Crop and number of strains ${ }^{1)}$} \\
\cline { 3 - 8 } & & Wheat & Barley & Oats & Maize & Alfalfa & Total \\
\hline 1914 & 4 & 2 & 0 & 0 & 12 & 3 & 17 \\
1915 & 2 & 7 & 0 & 0 & 0 & 0 & 7 \\
1916 & 36 & 89 & 12 & 175 & 0 & 0 & 276 \\
\hline Total & 42 & 98 & 12 & 175 & 12 & 3 & 300 \\
\hline
\end{tabular}

B. Distribution

\begin{tabular}{crrrrrrr}
\hline \hline \multirow{2}{*}{ Year } & No. cases & \multicolumn{7}{c}{ Crop and number of strains ${ }^{1)}$} \\
\cline { 2 - 8 } & & Wheat & Barley & Oats & Sorghum & Soybean & Total \\
\hline 1913 & 1 & 0 & 9 & 3 & 0 & 0 & 12 \\
1914 & 4 & 0 & 0 & 0 & 20 & 0 & 20 \\
1915 & 6 & 4 & 6 & 0 & 0 & 0 & 10 \\
1916 & 11 & 7 & 5 & 10 & 0 & 45 & 67 \\
\hline Total & 22 & 11 & 20 & 13 & 20 & 45 & 109 \\
\hline
\end{tabular}

1) These records were kept as carbon copies of the original letters at Minami's former laboratory of Crop Science, and are now kept at the University Archives, Hokkaido University.

after which their correspondence was discontinued, due to the hard social situation pertaining in Russia.

Probably stimulated by Flaksberger's letter of October, 1913, Minami started his own germplasm collection and distribution, as shown in Table 3.

Carbon copies of letters Minami sent to foreign institutions to request seeds and acknowledge their receipt are now kept in the University Archives, Main Library, Hokkaido University, from which I got information on the names of wheat varieties and those of their senders. Also, all wheat strains collected by Minami were recorded in his laboratory's notebook by their cultivar names or selection numbers, but none by their scientific names, except a few T. durum lines. Therefore, this group of Minami's wheat collection can be excluded as a source of the materials provided to Sakamura, because all of those materials were referred to by their scientific names. The remaining possibility is that the wheat stocks Sakamura obtained from Minami originated from the seeds that Minami received from Flaksberger sometime between October 7, 1915 and May 19, 1916.

Minami probably sowed the seeds of all 18 wheat varieties received from Flaskberger by May, 1916, among which spring-type varieties could be grown to flowering in that year, giving mature seeds in August of that year, although winter growth-type varieties are assumed not to have produced any mature seeds in that season. This means that Minami could not provide Sakamura with seeds of any winter-type varieties, which Minami might have received from Flaksberger. I did not find any record on the growth habit of Flaksberger's wheat varieties, and therefore cannot ascertain how many of the 18 varieties received from Flaksberger produced mature seeds in the fall of 1916 .
As described in the next section, Sakamura in his 1918 article reported chromosome numbers of eight wheat species, seeds of which were provided by Minami sometime between the end of 1916 and early spring of 1917 , before the sowing time of spring-type wheat in that year. If we assume that the seeds of wheat varieties studied by Sakamura originated from Flaksberger's wheat varieties sent to Minami, we can explain the gap between 18 varieties sent by Flaksberger and eight varieties studied by Sakamura by elimination of Flaksberger's winter-type varieties when Minami propagated them first in his experimental farm at Sapporo.

Another important point is what kind of conversation took place between Minami and Sakamura, when Sakamura asked Minami to supply wheat seeds to him. Although I could not find any information among the available documents on this important point, it is clear that if Minami provided Sakamura with a certain sample from his collection made in the 1914-1916 period, as shown in Table 3A, Sakamura could not have discovered the polyploid series of wheat, because Minami's wheat collection at that time consisted of only common and some emmer wheat cultivars. Minami appears to have correctly understood Sakamura's purpose of using the material that Minami was going to provide, and we should appreciate Minami's contribution on this important point.

Dr. Tetsu Sakamura (1988-1980):

His career as a cytologist and the possible source of his wheat materials

A photograph of Dr. Tetsu Sakamura is given in Fig. 1c, and his brief biography in Table 4, both of which are 
Table 4. Brief biography of Dr. T. Sakamura, from Toriyama (1982).

\begin{tabular}{cl}
\hline \hline \multicolumn{1}{c}{ Date } & \multicolumn{1}{c}{ Event } \\
\hline Oct., 1888 & Born in Hiroshima \\
July, 1913 & Graduated from Sapporo Agricultural College and advanced to the graduate course, College of Agriculture, Hokkaido University \\
July, 1918 & Published article on wheat chromosome numbers, discovering polyploidy \\
Aug., 1918 & Finished graduate course, College of Agriculture, Hokkaido University \\
Dec., 1918 & Began overseas studies for two years in USA and Europe, supported by the Ministry of Education, Japan \\
July, 1920 & Received Doctor's degree in Science from Hokkaido University \\
Apr., 1930 & Professor, College of Science, Hokkaido University \\
Apr., 1943 & Dean, College of Science, Hokkaido University \\
Feb., 1964 & Member, Japan Academy \\
Oct., 1980 & Died at the age of 92 \\
\hline
\end{tabular}

extracted from the "Memoir of Prof. Tetsu Sakamura" (in Japanese) that was edited by H. Toriyama (1982).

When Sakamura was a graduate student of Hokkaido University, he went to University of Tokyo several times in the period from 1914 to 1916, visiting Prof. Kenjiro Fujii, the founder of 'Cytologia', to obtain his advice on the studies of chromosome morphology and behavior, and also on his following three articles prepared in German, before his groundbreaking work on wheat chromosomes:

(1) Sakamura, T. (1914) Cell division of Vicia cracca L. (in German). Bot. Mag. (Tokyo) 28: 131-147. In this article, he reported mitosis in young floral organs and meiosis in pollen mother cells of $V$. cracca, a wild relative of $V$. faba.

(2) Sakamura, T. (1915) Chromosome bands in Vicia faba L. (preliminary report) (in German). Bot. Mag. (Tokyo) 29: 287-300. Here, he studied mitosis in root tip cells and meiosis in PMCs of $V$. faba, drawing the side and polar views of the metaphase and anaphase plates. In relation to his later wheat work, it is noteworthy that he mentioned the manuscript of Navashin's 1915 article, which reported haploid, diploid and triploid pollen nuclei in Crepis virens Vill. in its postscript.

(3) Sakamura, T. (1916) On the influence of chloral hydrate on cell and nuclear division-with special consideration on chromosome behavior (in German). Bot. Mag. (Tokyo) 2: 287-300. This article was a contribution from the Laboratory of Cytology and Genetics, Department of Plant Morphology, College of Science, Tokyo Imperial University; it provides strong evidence of his close relationship with Fujii's laboratory, which is not recorded in any of his official documents in either Hokkaido Uinversity or University of Tokyo.

The above three articles by Sakamura, published in 1914-1916, dealt with three species of the family Fabaceae, namely Vicia cracca, V. fava and Pisum sativum, whereas he suddenly changed his study material from dicotyledonous species to the monocotyledonous genus Triticum in his 1918 article, even though he remained a graduate student in the same laboratory in the Faculty of
Table 5. Chromosome numbers of Triticum species reported by Sakamura $(1918)^{1)}$.

\begin{tabular}{|c|c|c|c|c|c|}
\hline Species & Haploid & Diploid & Species & Haploid & Diploid \\
\hline T. vulgare & 21 & 42 & T. durum & - & 28 \\
\hline T. compactum & - & 42 & T. polonicum & - & 28 \\
\hline T. spelta ${ }^{2)}$ & - & 42 & T. dicoccum & - & 28 \\
\hline T. turgidum & - & 28 & T. monococcum & - & 14 \\
\hline
\end{tabular}

1) Haploid and diploid chromosome numbers were studied in meiosis of pollen mother cells and mitosis of root-tip cells, respectively.

${ }^{2)}$ This species name was written as T. Spelta by Sakamura.

Agriculture, Hokkaido University.

I did not find any documents that might explain why he changed his material at that time. However, I can speculate that his contact with Prof. Fujii and his graduate students in University of Tokyo stimulated him to change his material from dicotyledonous plants to economically important crops such as wheat in the Hokkaido area, with his confidence arising from the knowledge and skill which he had acquired by that time.

Sakamura's landmark work on wheat chromosomes can now be introduced, although first it is necessary to preview what was known about wheat chromosomes before he began this work. In fact, he listed the following articles by other workers that reported wheat chromosome numbers ahead of his own work:

Overton (1893); T. vulgare with $n=8$ and $2 n=16$,

Körnicke (1893); T. compactum with $n=8$,

Nakao (1911); T. vulgare with $n=8$, and

Bally (1912); T. vulgare and $T$. dicoccoides both with $n=8$.

In comparison with those results, Sakamura's observations, reported in his groundbreaking work of 1918, were distinctly different, as shown in Table 5.

Sakamura found $2 n=14,28$ and 42 chromosomes among eight Triticum species, discovering a $2 x, 4 x$ and $6 x$ polyploid series of the $2 n$ chromosome number. He studied gametic chromosome number $(n)$ only in $T$. vulgare (now T. aestivum), by observation of PMCs, whereas the somatic chromosome number $(2 n)$ of all eight species was observed with root-tip cells, probably in early spring of 1917; he asserted that root tips were 
Table 6. Comparison between the Triticum species studied by Flaksberger (1915) and Sakamura (1918), including those studied by Kihara (1924).

\begin{tabular}{|c|c|c|c|}
\hline Flaksberger (1915) & Sakamura (1918) & Kihara $(1924)^{1)}$ & Tanaka $(1983)^{2)}$ \\
\hline Tr. aegilopoides & (not tested) & T. aegilopoides (1920) & T. boeoticum KU101-1 \\
\hline Tr. monococcum & T. monococcum & T. monососсит (1920) & T. mоnососсит KU104-1 \\
\hline Tr. dicoccoides & (not tested) & T. dicoccoides (1920) & T. dicoccoides KU106-1 \\
\hline Tr. dicoccum & T. dicoccum & T. dicoccum (1920) & T. dicoccum KU111 \\
\hline Tr. durum & T. durum & T. durum (1922) & T. durum KU125 \\
\hline Tr. turgidum & T. turgidum & T. turgidum & T. turgidum KU147 \\
\hline Tr. polonicum & T. polonicum & T. polonicum (1922) & T. polonicum KU141 \\
\hline Tr. Spelta ${ }^{3)}$ & T. Spelta ${ }^{3)}$ & T. Spelta ${ }^{3)}$ (1922) & T. spelta KU157 \\
\hline Tr. vulgare & T. vulgare & T. vulgare (1920) & T. aestivum KU163 \\
\hline Tr. compactum & T. compactum & T. compactum & T. compactum $^{4)}$ KU150 \\
\hline- & - & - & T. compactum ${ }^{5)} \mathrm{KU} 151$ \\
\hline
\end{tabular}

Note) Two species, T. aegilopoides and T. dicoccoides, are wild species, whereas all others are cultivated species.

${ }^{1)}$ Kihara (1924) mentioned that all species, including two wild species, were gratefully received from Sakamura (footnote on page 18 of his 1924 article). The year given after each species indicates when it was first used in Kihara's 1924 work.

2) Wheat accessions obtained by Kihara from Hokkaido University, when he established the new Genetics Laboratory in Kyoto University, and registered with a Kyoto University (KU) accession number in 1927 (from Tanaka 1983).

3) All three authors (Flaksberger, Sakamura and Kihara) wrote "Spelta" in the same manner.

4),5) T. compactum var. icterinum and var. humboldtii, respectively.

Table 7. Presumed time course of the events between Minami's request to Flaksberger for Russian wheat seeds and Sakamura's publication of the correct wheat chromosome numbers.

\begin{tabular}{|c|c|}
\hline Event & Date \\
\hline Minami's request to Flaksberger for Russian wheat & Oct. 7,1915 \\
\hline Minami's acknowledgement of receiving wheat seeds from Flaksberger & May 19,1916 \\
\hline Minami's first propagation of Flaksberger's wheat in Sapporo & May-Sept., 1916 \\
\hline Minami's supply of wheat seeds to Sakamura & Nov., 1916-Jan., 1917 \\
\hline Sakamura's observation of root-tip mitosis & Feb.-April, 1917 \\
\hline Sakamura's wheat seedling transplantation into the field & May, 1917 \\
\hline Sakamura's PMC observation and crossing of wheat species of different ploidies & Aug., 1917 \\
\hline Summarizing the results of chromosome observation by Sakamura & Oct.-Nov., 1917 \\
\hline Submission of Sakamura's manuscript to Botanical Magazine (Tokyo) & Dec., 1917 \\
\hline Growing $F_{1}$ hybrids and their parental stocks in the field by Sakamura & May-Sept., 1918 \\
\hline Publication of the results on chromosome number of eight wheat species, discovering polyploidy & July, 1918 \\
\hline Transfer of all Sakamura's materials to Kihara & Aug., 1918 \\
\hline Sakamura's departure for overseas study & Dec., 1918 \\
\hline
\end{tabular}

favorable material for chromosome observation because they contain many dividing cells.

He was appointed as an overseas scholar by the Ministry of Education, Japan, and was expected to leave Japan at the end of the summer of 1918 for a two-year study period in USA, England and Sweden. He was therefore looking for a successor to take over his wheat material and found H. Kihara, who had just enrolled as a graduate student in the laboratory to which Sakamura belonged (for some reason, Sakamura's departure was delayed until the end of that year).

Sakamura observed chromosomes in root-tip cells of all eight species before their field planting in 1917, and observed meiotic chromosomes in PMCs only in $T$. vulgare (later $T$. aestivum). He prepared a manuscript reporting the results of chromosome observation of the above materials, which was submitted in the later part of 1917 to the Bot. Mag. (Tokyo) and published in July, 1918 , before his departure for the overseas study in December, 1918, just 100 years ago.
In addition, he made crosses in the summer of 1917 , in the following four cross combinations (namely, $4 x$ female $\times 6 x$ male parents), expecting to obtain information on what kinds of chromosome numbers would be recovered in their offspring:

(1) T. durum (우) $\times$ T. vulgare $\left(\sigma^{7}\right)$

(2) T. turgidum $($ 우 $) \times T$. compactum $\left(\sigma^{\top}\right)$

(3) T. polonicum $($ 우 $) \times$ T. spelta $\left(\sigma^{\top}\right)$

(4) T. polonicum $($ 우 $) \times T$. compactum $\left(\sigma^{\top}\right)$

The $\mathrm{F}_{1}$ hybrids produced from those crosses were grown in the field in the summer of 1918, and were transferred to Kihara, with their parental lines, before Sakamura's departure for overseas study in December, 1918.

Next, I will compare the species studied by Flaksberger (1915) and those by Sakamura (1918). The result of this comparison is shown in Table 6, in which the species list of Flaksberger is shown in the leftmost column, and the species studied by Sakamura and Kihara are in the two middle columns. As a reference, wheat stocks 
Table 8. Brief biography of Dr. H. Kihara, from "Select Papers of Dr. H. Kihara" (Kihara 1980).

\begin{tabular}{ll}
\hline \multicolumn{1}{c}{ Date } & \\
\hline $\begin{array}{l}\text { Oct., 1893 } \\
\text { July, 1918 }\end{array}$ & $\begin{array}{l}\text { Born in Tokyo } \\
\text { Graduated from College of Agriculture, Hokkaido University, Sapporo }\end{array}$ \\
Oct., 1918 & Advanced to Graduate School, College of Agriculture, Hokkaido University \\
Mar., 1924 & Assistant, College of Science, Kyoto University \\
Apr., 1924 & Publication of Doctoral Dissertation in Memoirs of College of Science, Kyoto University \\
July, 1924 & Obtained Doctor's Degree in Science, Kyoto University \\
Sept., 1924 & Overseas study in Europe and USA \\
June, 1927 & Returned from the overseas study; Professor of Kyoto University \\
May, 1943 & Imperial Award, Japan Academy \\
Jan., 1944 & President, Genetics Society of Japan \\
Oct., 1949 & Member, Japan Academy \\
Oct., 1955 & Director, National Institute of Genetics, Japan (to Mar., 1969) \\
Apr., 1960 & Trustee, International Rice Research Institute, Philippines \\
Dec., 1964 & Director, Plant Virus Research Institute, Ministry of Agriculture, Forestry and Fisheries, Japan \\
July, 1986 & Died at the age of 92 \\
\hline
\end{tabular}

Note) Dr. Kihara was elected as an honorary member of many scientific academies or societies, including the Swedish Society of Genetics (Dec., 1935), Royal Academy of Denmark (Apr., 1956), Royal Physiological Society of Lund (Nov., 1956), National Academy of Sciences, USA (Apr., 1958), German Academy, Leopoldina (Oct., 1960), Philosophical Society of USA (Apr., 1965), and British Genetics Society (Nov., 1967).

that Kihara received from Hokkaido University, when he was promoted to become the professor in charge of the newly established Laboratory of Genetics, in the College of Agriculture, Kyoto University, are shown in the rightmost column.

This comparison indicates complete coincidence between the two lists of Flaksberger's and Sakamura/Kihara's, suggesting that their materials belonged to the same source. This coincidence is the most important evidence that the source of Sakamura/Kihara's wheat materials was the seeds provided in early 1916 by Flaksberger in Russia to Minami in Japan.

Next, I will consider a possible time course for the events that occurred between Minami's request for Russian wheat seeds to Flaksberger and Sakamura's publication on the correct wheat chromosome number, as summarized in Table 7.

The information summarized in Table 7 indicates that the wheat stocks sent from Flaksberger to Minami, who initially propagated them at Hokkaido University and then provided them to Sakamura, were available for Sakamura to observe their root-tip mitosis, with one species for PMC observation, and to make crosses in four combinations between $4 x$ and $6 x$ species in the summer of 1917: these postulated events fit the assumption that Flaksberger's wheat stocks sent to Minami were used in Sakamura's work to discover the correct wheat chromosome numbers.

Dr. Hitoshi Kihara (1893-1986), the inheritor of Sakamura's materials, becomes the founder of genome analysis

Kihara's photograph and his brief biography are given in Fig. 1d and Table 8, respectively. As described in the previous section, Kihara accepted Sakamura's offer to take over his materials, starting the work with $5 x$ hybrids that had already been grown in the field of Hokkaido University in 1918. In addition to these $F_{1}$ hybrids that Sakamura produced, Kihara himself made crosses to produce two triploid $\mathrm{F}_{1}$ hybrids, T. dicoccum ( $4 x$ species $) \times T$. monococcum $(2 x)$ and $T$. aegilopoides $(2 x) \times T$. dicoccum $(4 x)$. He analyzed meiotic chromosome behavior of all these hybrids, and thus determined their genome constitutions by investigating meiotic behavior and somatic chromosome numbers of their offspring; this work opened a new era of genome analysis.

When Kihara moved to Kyoto University in October, 1920, he received from Hokkaido University all the wheat species that Sakamura studied, as stated above, and extended his genome analytical work to include all species of the two genera Triticum and Aegilops; genome analysis of the genus Triticum was completed in 1951 (Lilienfeld and Kihara 1934, Lilienfeld 1951), and that of the genus Aegilops by Kihara (1949), the latter complemented by a study of its four hexaploid species by Kihara and Tanaka (1970).

One of the highlights of Kihara's work on genome analysis is his demonstration of the genome as a functional unit of heredity; competition observed between gametes having different numbers of D-genome chromosomes, from zero to seven, in the fertilization of $5 x$ hybrids (AABBD genomes) indicated a clear advantage for gametes having euploid chromosome numbers $(n=14$ with $\mathrm{AB}$ genomes and $n=21$ with $\mathrm{ABD}$ genomes) and a slight advantage for nearly euploid chromosome numbers $(n=\mathrm{AB}+1$, or ABD- 1$)$ over all the other chromosome numbers. Figure 3 shows the results of artificial backcrosses of the pentaploid hybrid ( $T$. polonicum $\times T$. spelta) $\mathrm{F}_{1}$, as female (Figure $3 \mathrm{~A}$ ) or as male parent (Fig. 
A

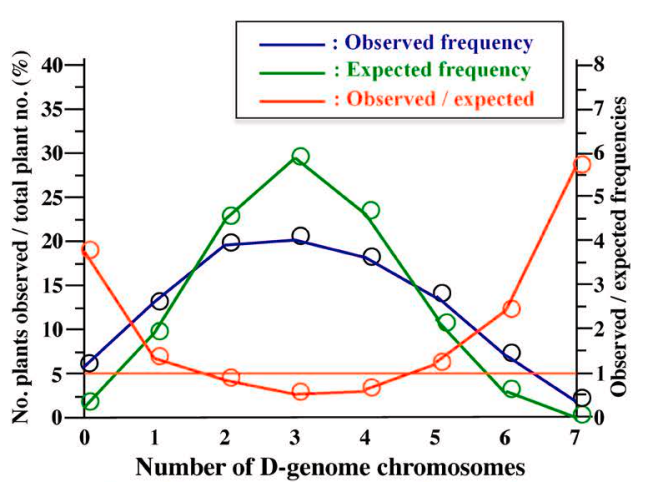

B

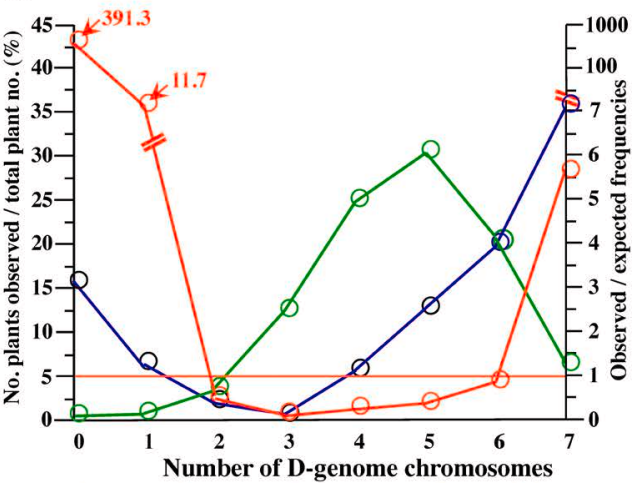

Fig. 3. Female and male transmission of the D-genome univalent chromosomes in reciprocal crosses between T. polonicum $\times$ T. spelta $\mathrm{F}_{1}(\mathrm{AABBD}, 2 n=35)$ and $T$. polonicum $(\mathrm{AABB}, 2 n=28)$. A) $\mathrm{F}_{1}$ hybrid $\times T$. polonicum $\left(\sigma^{7}\right)$, determined from the pooled data of Kihara and Wakakuwa (1935) and Matsumura (1940). B) T. polonicum (우) $\times \mathrm{F}_{1}$ hybrid, determined from Matsumura (1936).

3B), to T. polonicum as the other parent (Kihara and Wakakuwa 1935, Matsumura 1940).

In the reciprocal cross between $4 x$ wheat as female and $5 x$ hybrid as pollen parent, frequencies of the eutetra- or eupentaploids $(2 n=28, \mathrm{AABB}$, or $2 n=35$, AABBD) were much higher than those expected from the average transmission rate of $\mathrm{D}$-genome chromosomes (Fig. 3B). In particular, male gametes missing all the D-genome chromosomes $(n=14, \mathrm{AB})$ or having a single $\mathrm{D}$-genome chromosome in addition to $\mathrm{AB}$ genomes $(n=15, \mathrm{AB}+1 \mathrm{D})$ showed a much higher fertilization ability compared to those of the reciprocal cross. These results critically demonstrated that the complete set of D-genome chromosomes is the functional unit of fertilization in both sexes, although the advantage of complete absence of D-genome univalents is much more pronounced in the male gamete. Thus, we must recognize the genome not only as the distinct genetic unit of chromosome transmission but also as the unit of function, at least in fertilization of both female and male gametes, and this is one of the distinctive contributions of Kihara's genome concept.

The conclusion that the set of seven D-genome chromosomes is the functional unit in fertilization was further supported by the results of repeated self-pollination of the pentaploid hybrids as shown in Fig. 4.

This result showed that the progeny of pentaploid wheat hybrids settled, after repeated self-pollination, at either eutetraploid with $\mathrm{AABB}$ or euhexaploid with AABBDD genome composition, with an exceptional hypohexaploid with $2 n=40$, forming 20 ", that correspond to the nullisomics of D-genome chromosomes (Sears 1954).

At this stage, Kihara became interested in the interaction between genome and cytoplasm, making repeated backcrosses of an $\mathrm{F}_{1}$ hybrid, Ae. caudata $(2 n=14$, genome $\mathrm{CC}) \times T$. aestivum, with $T$. aestivum as the recurrent pollen parent, up to the eighth substitution backcross $\left(\mathrm{SB}_{8}\right)$ generation in 1959 , as shown in Fig. 5

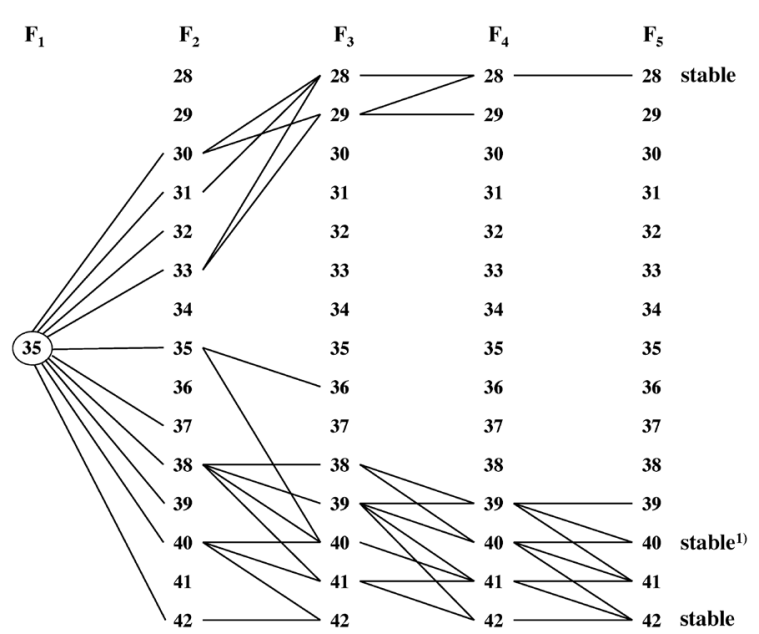

Fig. 4. Convergence of the somatic chromosome number to either tetraploid $(4 x)$ or hexaploid $(6 x)$ in the self-pollinated progeny, $\mathrm{F}_{2}$ to $\mathrm{F}_{5}$, of a pentaploid hybrid having the genome constitution AABBD. ${ }^{1)}$ Exceptional, stable $\mathrm{F}_{5}$ lines arose with $2 n=40$, forming 20 bivalents at the meiotic metaphase (Kihara 1924), that correspond to the nullisomics of D-genome chromosome (Sears 1954).

(Kihara 1951, 1959).

This strain showed complete pollen sterility at the $\mathrm{SB}_{3}$ generation, maintaining the sterility until the $\mathrm{SB}_{8}$ generation (dashed black line), whereas the plants of these generations showed normal seed setting when pollinated with pollen of normal Tve wheat, indicating normal female fertility (solid black line). In contrast, the $\mathrm{F}_{1}$ hybrid, T. aestivum $\times$ Ae. caudata, recovered normal fertility of both the female and male gametes in the second or third restitution backcross generation, keeping their normal fertility until the $\mathrm{RB}_{8}$ generation (solid and dashed red lines in Fig. 5); these results clearly indicated that the cytoplasm of Ae. caudata induced male sterility in a common wheat, leading to the discovery of cytoplasmic male sterility in common wheat. This finding stimulated wheat breeders to start hybrid wheat breeding, which was reinforced by the discovery of the same 


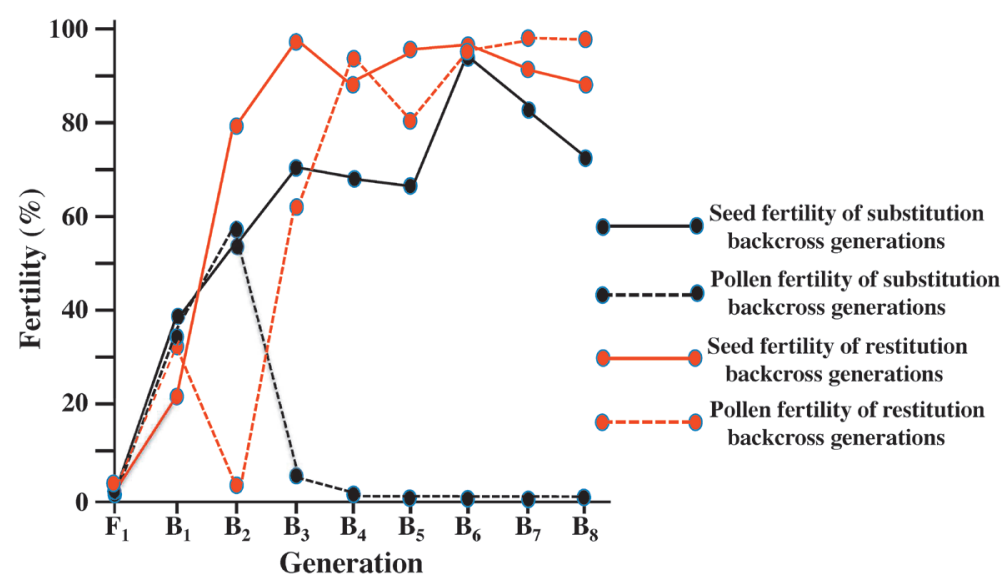

Fig. 5. Discovery of cytoplasmic male sterility induced by the cytoplasm of Aegilops caudata in a common wheat, T. aestivum var. erythrospermum strain 'Tve' (Kihara 1959): Tve wheat with the caudata cytoplasm became pollen-sterile in the $\mathrm{SB}_{3}$ to $\mathrm{SB}_{8}$ generations, but showed normal female fertility when backcrossed with the 'Tve' pollen.

Table 9. Number of alloplasmon sources provided by other research groups, and those produced by Tsunewaki's group.

\begin{tabular}{llc}
\hline \hline \multicolumn{1}{c}{ Provider } & \multicolumn{1}{c}{ Institution $^{1)}$} & Number of alloplasmons \\
\hline Sakamoto, S. & Nat. Inst. Genet., Japan & 8 \\
Panayotov, I. & Wheat and Sunflower Res. Inst., Bulgaria & 8 \\
Maan, S. S. & North Dakota State Univ., Fargo, USA & 7 \\
Kihara, H. & Kihara Inst. Biol. Res., Yokohama, Japan & 2 \\
Others ${ }^{2}$ & - & 5 \\
Subtotal & - & 30 \\
Tsunewaki, K. & Kyoto Univ./ Fukui Pref. Univ., Japan & 16 \\
\hline \multicolumn{1}{c}{ Total } & \multicolumn{1}{c}{-} & 46 \\
\hline
\end{tabular}

1) Their affiliations when they provided the indicated alloplasmic lines to Tsunewaki.

2) One alloplasmon was provided by each of H. Fukasawa, Kobe Univ., M. Muramatsu, Okayama Univ., I. Ohtsuka and T. Sasakuma, both of Kihara Inst. Biol. Res., Yokohama, all in Japan, and J. W. Schmidt, Univ. Nebraska, Lincoln, Nebraska, USA.

phenomenon induced by $T$. timopheevi cytoplasm by Wilson and Ross (1962). This T. aestivum strain, whose abbreviation is "Tve" after Kihara (1959), was one of the 18 wheat strains provided by Flaksberger to Minami in the 1915-1916 period and was studied by Sakamura in 1917-1918. Kihara continued its backcrossing with Tve pollen up to $\mathrm{SB}_{17}$, in 1966, and, after that I continued its backcrossing up to the $\mathrm{SB}_{63}$ generation in 2017, proving continuation of the male sterility of this alloplasmic wheat line until now.

K. Tsunewaki's group, extending Kihara's work on an alien cytoplasm to plasmon analysis of the Triticum-Aegilops complex

Hereafter, I will use the term plasmon, instead of 'cytoplasm,' to indicate the genetic entity present in the cytoplasm, after the proposal of von Wettstein (1926). Before describing our results on plasmon analysis, I will explain the notation used to describe an alloplasmic line in which plasmon and genome differ in their origin, and the degree of genome homozygosity, which depends upon the number of substitution backcrosses made before its use. For this purpose, we developed the following unified system for designation of an alloplasmic line: an alloplasmic line having genome and plasmon derived from different species (or strains) is indicated by a formula consisting of the name of the plasmon donor in parentheses and the species name or genome symbol of the genome donor, connecting the two names with a hyphen. When necessary to indicate genetic homozygosity of the genome, the number of substitution backcrosses made with the same recurrent pollen parent is given by a subscript added to SB (for substitution backcrosses, where 'substitution' means nucleus substitution), or by a superscript added to the name of the genome donor. For example, an alloplasmic line of 'Tve' wheat with $A e$. caudata plasmon at its 50th backcross generation is written as either (caudata)-Tve $\mathrm{SB}_{50}$ or (caudata)-Tve ${ }^{51}$, '51' being the sum of the first cross producing the initial $F_{1}$ hybrid and the following 50 repeated substitution backcrosses, in all of which the same genome donor was used as the pollen parent.

Transfer of alloplasmons to wheat was started almost 
Table 10. Source of the Aegilops and Triticum plasmons used by Tsunewaki's group to produce alloplasmic lines of 12 common wheat strains ${ }^{1)}$ (Tsunewaki et al. 1996).

\begin{tabular}{|c|c|c|c|c|c|c|c|}
\hline \multicolumn{5}{|c|}{ Plasmon } & \multicolumn{3}{|c|}{ Origin of plasmon } \\
\hline Abbrev. & Code & Provider $^{1)}$ & Year $^{2)}$ & Type $^{3)}$ & Taxonomic name & Chromosome number $(n)$ & Genome $^{4)}$ \\
\hline \multicolumn{8}{|c|}{ A. Genus Aegilops: } \\
\hline \multicolumn{8}{|c|}{ Sect. Cylindropyrum } \\
\hline$c d t 1$ & 02 & Kihara & 1965 & $\mathrm{C}$ & Ae. caudata polyathera KU6-1 & 7 & $\mathrm{C}$ \\
\hline$c d t 2$ & 27 & Tsunewaki & 1972 & $\mathrm{C}$ & Ae. caudata $^{5)}$ & 7 & $\mathrm{C}$ \\
\hline$c y l$ & 28 & Tsunewaki & 1965 & $\mathrm{D}$ & Ae. cylindrica & 14 & $\mathrm{CD}$ \\
\hline \multicolumn{8}{|c|}{ Sect. Vertebrata } \\
\hline$s q r 1$ & 04 & Kihara & 1971 & $\mathrm{D}$ & Ae. squarrosa typica KU20-2 & 7 & $\mathrm{D}$ \\
\hline$s q r 2$ & 19 & Sasakuma & 2009 & $\mathrm{D}$ & Ae. squarrosa anathera KU2009 & 7 & $\mathrm{D}$ \\
\hline$v n t$ & 36 & Tsunewaki & 1967 & $\mathrm{D}$ & Ae. ventricosa KU22-4 & 14 & $\mathrm{DN}$ \\
\hline $\operatorname{crs} 1$ & 35 & Maan & 1977 & $\mathrm{D}^{2}$ & Ae. crassa $4 x$ & 14 & $\mathrm{DM}$ \\
\hline $\operatorname{crs} 2$ & 55 & Sakamoto & 1968 & $\mathrm{D}^{2}$ & Ae. crassa $6 x$ KU21-4 & 21 & $\underline{\mathrm{DDM}}$ \\
\hline$v v l$ & 56 & Ohtsuka & 1973 & $\mathrm{D}^{2}$ & Ae. vavilovii & 21 & $\overline{\mathrm{DMS}}$ \\
\hline jvn & 53 & Sakamoto & 1972 & $\mathrm{D}^{2}$ & Ae.juvenalis & 21 & $\overline{\mathrm{DMU}}$ \\
\hline \multicolumn{8}{|c|}{ Sect. Comopyrum } \\
\hline $\mathrm{cms}$ & 05 & Tsunewaki & 1973 & M & Ae. comosa thessalica KU17-2 & 7 & M \\
\hline hld & 06 & Panayotov & 1976 & $\mathrm{M}^{\mathrm{h}}$ & Ae. heldreichii & 7 & M \\
\hline$u n r$ & 07 & Maan & 1977 & $\mathrm{~N}$ & Ae. uniaristata & 7 & $\mathrm{~N}$ \\
\hline \multicolumn{8}{|c|}{ Sect. Amblyopyrum } \\
\hline$m t c 1$ & 13 & Maan & 1977 & $\mathrm{~T}$ & Ae. mutica & 7 & $\mathrm{~T}$ \\
\hline$m t c 2$ & 14 & Panayotov & 1977 & $\mathrm{~T}^{2}$ & Ae. mutica & 7 & $\mathrm{~T}$ \\
\hline \multicolumn{8}{|c|}{ Sect. Sitopsis } \\
\hline spl1 & 08 & Tsunewaki & 1965 & $\mathrm{~S}$ & Ae. speltoides ligustica & 7 & $\mathrm{~S}$ \\
\hline spl2 & 15 & Maan & 1977 & $\mathrm{G}^{\prime}$ & Ae. spelotides ligustica & 7 & $\mathrm{~S}$ \\
\hline spl3 & 09 & Panayotov & 1976 & $\mathrm{G}$ & Ae. speltoides aucheri & 7 & $\mathrm{~S}$ \\
\hline spl4 & 17 & Tsunewaki & 1980 & $\mathrm{~S}$ & Ae. speltoides aucheri KU2201B & 7 & $\mathrm{~S}$ \\
\hline$b c r$ & 12 & Maan & 1977 & $\mathrm{~S}^{\mathrm{b}}$ & Ae. bicornis & 7 & $S^{b}$ \\
\hline$s h r$ & 10 & Sakamoto & 1969 & $S^{1}$ & Ae. sharonensis KU5-1 & 7 & $\mathrm{~S}^{1}$ \\
\hline $\operatorname{lng}$ & 20 & Tsunewaki & 1976 & $S^{1 \prime}$ & Ae. longissima TL05 & 7 & $S^{1}$ \\
\hline $\operatorname{srs}$ & 18 & Tsunewaki & 1982 & $\mathrm{~S}^{\mathrm{v}}$ & Ae. searsii & 7 & $\mathrm{~S}^{\mathrm{s}}$ \\
\hline \multicolumn{8}{|c|}{ Sect. Polyeides } \\
\hline$u m b$ & 03 & Muramatsu & 1972 & $\mathrm{U}$ & Ae. umbellulata & 7 & $\mathrm{U}$ \\
\hline $\operatorname{trn} 1$ & 26 & Tsunewaki & 1966 & $\mathrm{U}$ & Ae. triuncialis & 14 & $\mathrm{UC}$ \\
\hline $\operatorname{trn} 2$ & 38 & Panayotov & 1976 & $\mathrm{C}^{\prime}$ & Ae. triuncialis & 14 & $\mathrm{UC}$ \\
\hline bnc1 & 29 & Sakamoto & 1969 & $\mathrm{U}$ & Ae. biuncialis KU12-1 & 14 & $\mathrm{UM}$ \\
\hline$b n c 2$ & 37 & Panayotov & 1976 & $\mathrm{U}$ & Ae. biuncialis macrochaeta & 14 & $\mathrm{U} \underline{\bar{M}}$ \\
\hline$c l m$ & 30 & Sakamoto & 1969 & $\mathrm{U}^{\prime}$ & Ae. columnaris KU11-2 & 14 & $\underline{\mathrm{UM}}$ \\
\hline ovt & 31 & Fukasawa & 1961 & $\mathrm{M}^{\mathrm{o}}$ & (Ae. ovata)-N26 $\mathrm{SB}_{7}$ & 14 & $\mathrm{UM}$ \\
\hline $\operatorname{trr} 1$ & 32 & Tsunewaki & 1972 & $\mathrm{U}$ & Ae. triaristata $4 x$ & 14 & $\mathrm{U} \underline{\bar{M}}$ \\
\hline $\operatorname{trr} 2$ & 54 & Sakamoto & 1968 & $\mathrm{U}$ & Ae. triaristata $6 x$ KU10-1 & 21 & $\mathrm{U} \overline{\mathrm{MN}}$ \\
\hline $\operatorname{trr} 3$ & 57 & Panayotov & 1976 & $\mathrm{U}$ & Ae. triaristata recta $6 x$ & 21 & $\mathrm{UMN}$ \\
\hline$k t s 1$ & 33 & Sakamoto & 1968 & $\mathrm{~S}^{\mathrm{v}}$ & Ae. kotschyi KU14-2 & 14 & $\overline{\mathrm{US}}$ \\
\hline$k t s 2$ & 39 & Tsunewaki & 1986 & $\mathrm{~S}^{\mathrm{v}}$ & Ae. kotschyi KUSE927 & 14 & $\mathrm{U} \overline{\mathrm{S}}$ \\
\hline$v r b$ & 34 & Sakamoto & 1968 & $\mathrm{~S}^{\mathrm{v}}$ & Ae. variabilis KU13-1 & 14 & $\mathrm{U} \underline{\bar{S}}$ \\
\hline \multicolumn{8}{|c|}{ B. Genus Triticum } \\
\hline$b t c$ & 01 & Tsunewaki & 1964 & A & T. boeoticum aegilopoides & 7 & A \\
\hline$m n c$ & 16 & Panayotov & 1980 & $\mathrm{~A}^{2}$ & T. monococcum flavescens & 7 & $\mathrm{~A}$ \\
\hline$d c d$ & 21 & Tsunewaki & 1966 & B & T. dicoccoides spontaneonigrum & 14 & $\mathrm{AB}$ \\
\hline$d c m$ & 22 & Tsunewaki & 1965 & $\mathrm{~B}$ & T. dicoccum 'Vernal' & 14 & $\mathrm{AB}$ \\
\hline $\operatorname{arr} 1$ & 23 & Tsunewaki & 1969 & G & T. araraticum & 14 & AG \\
\hline $\operatorname{arr} 2$ & 24 & Maan & 1977 & $\mathrm{G}$ & T. araraticum & 14 & $\mathrm{AG}$ \\
\hline tmp & 25 & Schmidt & 1962 & G & T. timopheevi & 14 & $\mathrm{AG}$ \\
\hline$z h k$ & 51 & Maan & 1977 & $\mathrm{G}$ & T. zhukovskyi & 21 & AAG \\
\hline ast 1 & 52 & (euplasmic) & 1965 & B & common wheat (control $\left.{ }^{6)}\right)$ & 21 & $\mathrm{ABD}$ \\
\hline ast 2 & 11 & Panayotov & 1976 & B & T. aestivum 'Penjamo' & 21 & $\mathrm{ABD}$ \\
\hline ast 3 & 58 & Tsunewaki & 1984 & B & T. aestivum tibetanum & 21 & $\mathrm{ABD}$ \\
\hline
\end{tabular}

${ }^{1)}$ Provider of an alloplasmic wheat line having the respective alloplasmon to produce alloplasmic lines of 12 common wheat strains, A-L.

2) Year received from the provider, or year when the first cross for producing alloplasmic common wheat testers was made by Tsunewaki.

3) Plasmon types proposed by Tsunewaki (2009), with minor changes of indicating four subtype plasmons identified in this article.

4) Nuclear genome symbols proposed by Kimber and Tsunewaki (1988).

${ }^{5)}$ A synthetic tetraploid, having the genome constitution CCUU, produced from an Ae. caudata (우) $\times$ Ae. umbellulata ( $\left.0^{7}\right) \mathrm{F}_{1}$ hybrid.

6) Twelve tester strains of common wheat (see Table 11). 
Table 11. Twelve common wheat strains $(2 n=6 x=42$, genome constitution AABBDD) used as the recipients of 46 alloplasmons (Tsunewaki et al. 1996).

\begin{tabular}{|c|c|c|}
\hline Code & Alloplasmon recipient & Abbrev. \\
\hline A & T. aestivum var. erythrospermum ${ }^{1)}$ & Tve \\
\hline B & T. aestivum strain $\mathrm{P} 168^{2)}$ & P168 \\
\hline $\mathrm{C}$ & T. aestivum cv. Chinese Spring & $\mathrm{CS}$ \\
\hline $\mathrm{D}$ & T. aestivum cv. Norin 26 & $\mathrm{~N} 26$ \\
\hline $\mathrm{E}$ & T. aestivum strain Salmon ${ }^{3)}$ & Slm \\
\hline $\mathrm{F}$ & T. aestivum cv. Jones Fife & $\mathrm{JF}$ \\
\hline G & T. aestivum cv. Selkirk & $\mathrm{Sk}$ \\
\hline $\mathrm{H}$ & T. aestivum cv. S-615 & S615 \\
\hline I & T. sphaerococcum var. rotundatum & Sphr \\
\hline $\mathrm{J}$ & T. compactum cv. No. $44^{1)}$ & Cmp \\
\hline $\mathrm{K}$ & T. spelta var. duhamelianum ${ }^{1)}$ & Splt \\
\hline $\mathrm{L}$ & T. macha var. subletschchumicum & Mch \\
\hline
\end{tabular}

1) These three alloplasmon recipients belong to the Flaksberger/ Minami stocks.

2) A hexaploid derivative having a single chromosome substitution obtained in the self-pollinated offspring of the $\mathrm{F}_{1}$ hybrid, T. aestivum var. erythrospermum $\times$ Ae. caudata var. polyathera (genome constitution, ABCD), having 1B (?)/C-sat-2 chromosome substitution (Kihara 1959).

3) A spontaneous hexaploid derivative having AABBDD genome constitution, obtained by Tsunewaki (1964) in the offspring of an octoploid triticale (genome AABBDDRR) produced by B. C. Salmon, USDA, Beltsville, USA.

at the same time in three research groups in the world, after Kihara's pioneering work $(1951,1959)$ that was assisted by S. Sakamoto: by Maan and Lucken's group in North Dakota State University, Fargo, USA, initiated by Maan (1975), Panayotov and Gotsov's group in the Wheat and Sunflower Institute, Tolbuhin, Bulgaria, initiated by Panayotov and Gotsov (1976), and our group in Kyoto University, Kyoto, Japan, started by Tsunewaki and Endo (1973).

At an early stage of our plasmon analysis, I obtained 30 alloplasmon sources mainly from those groups, as shown in Table 9.

In total, 46 alloplasmons became available for our use, which covered all species of the Triticum-Aegilops complex (Table 10) except T. urartu, for which plasmon could not be transferred to polyploid wheat even with the embryo rescue technique applied to young embryos of the cross T. urartu (ㅇ) $\times$ T. durum (Tsunewaki et al. 1999).

The next step was to choose wheat strains to be used as the recipient of these alloplasmons. For this purpose, I selected hexaploid instead of tetraploid wheat, because of the easiness in repeating substitution backcrosses for alloplasmon transfer to this group of wheat, sacrificing to some extent the sensitivity to detect genetic differences between plasmons. Thus, I used 12 common wheat strains as the alloplasmon recipients that covered a wide variation in the morphology and physiology of common wheat, as shown in Table 11, in which three lines descended from Flaksberger's stock were included.

As shown in Table 12, the total number of alloplasmic lines produced by 1996 was 552; in all possible
Table 12. Substitution backcross (SB) generations of 552 alloplasmic lines of common wheat, produced in all possible combinations between the 12 tester wheat genotypes and 46 alloplasmons, attained in 1996 by their repeated substitution backcrosses (Tsunewaki et al. 1996).

\begin{tabular}{ccc}
\hline \hline SB generation reached & No. alloplasmic lines & Percent of total \\
\hline $\mathrm{SB}_{4}-\mathrm{SB}_{9}$ & $7^{1)}$ & 1.3 \\
$\mathrm{SB}_{10}-\mathrm{SB}_{14}$ & 499 & 90.4 \\
$\mathrm{SB}_{15}-\mathrm{SB}_{19}$ & 34 & 6.2 \\
$\mathrm{SB}_{20}-\mathrm{SB}_{29}$ & 10 & 1.8 \\
$\mathrm{SB}_{30} \& \mathrm{SB}_{42}$ & $2^{2)}$ & 0.4 \\
\hline Total & 552 & 100.1 \\
\hline
\end{tabular}

1) Alloplasmic lines not reaching the $\mathrm{SB}_{10}$ generation before 1996 were (boeoticum)-Tve, -P168, -N26, -JF -S615 and -Sphr, and (longissima)-Mch.

2) The two alloplasmic lines reaching the $\mathrm{SB}_{30}$ and $\mathrm{SB}_{42}$ generation are $(c d t 1)-\mathrm{CS}$ and -Tve, respectively.

combinations between 46 alloplasmons and 12 plasmon testers, 545 lines $(98.7 \%)$ reached the $\mathrm{SB}_{10}$ or more advanced backcross generations; the two most advanced lines in repeating the backcrosses were $(c d t 1)$-CS and -Tve at $\mathrm{SB}_{30}$ and $\mathrm{SB}_{42}$, respectively, whose breeding was started by Kihara prior to our work. In contrast, seven lines did not reach the $\mathrm{SB}_{10}$ generation by 1996; six of these have the same T. boeoticum plasmon that retarded growth of lines having this plasmon, thus often missing the chance of repeating the backcross with their recurrent pollen parents.

We studied genetic effects of all the plasmons on the following 19 phenotypic characters of 12 common wheat testers in four replications, except for two characters (pollen fertility and self-pollinated seed fertility of greenhouse-grown plants) that were observed with no replications (Tsunewaki et al. 2002): (1) winter variegation, (2) growth vigor in early spring, (3) heading date, (4) plant height at maturity, (5) ear number per plant, (6) culm length of the three tallest culms, (7-10) lengths of the 1 st to 4 th internodes from the top, (11) ear length, (12) spikelet number per ear, (13) culm diameter of the 2nd internode from the top in two culms per plant, (14) dry weight of two air-dried culms per plant, $(15,16)$ self-pollinated seed fertilities of the 1st and 2nd florets of the two bagged ears before flowering, in both fieldand greenhouse-grown plants, (17) pollen fertility showing the proportion of pollen grains having one vegetative and two wedge-shaped male nuclei among 300-500 pollen grains, (18) seed fertility showing the proportion of seed-bearing florets among artificially pollinated florets, and (19) seed germination rate, in all 12 tester wheat lines; two further characters, i.e., (20) frequency of haploid plants and (21) that of twin seedlings, were observed only in a single tester, Salmon (Tsunewaki et al. 1996, 2002).

Among the above 21 phenotypic characters, I will mention here only one character, namely, seed setting rate under self-pollination in the field-grown plants, 

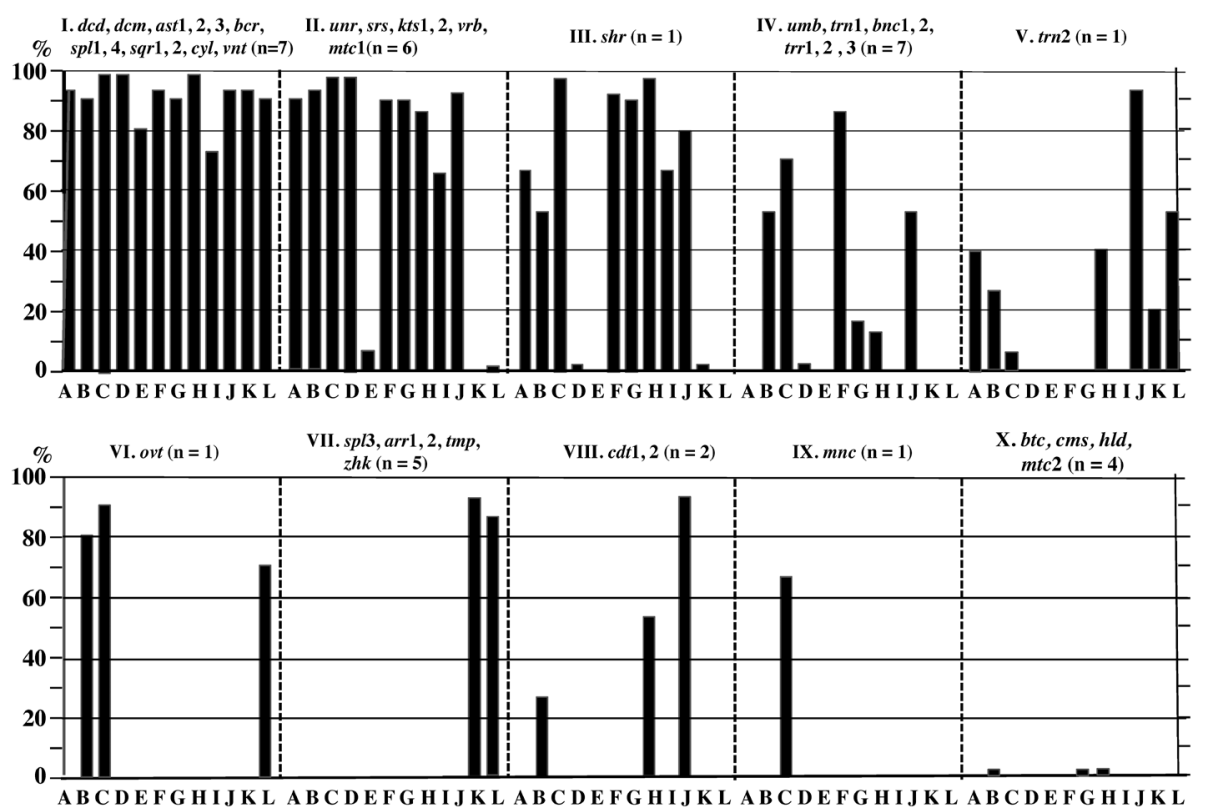

Fig. 6. Ten major self-pollinated seed fertility spectra, I to X, which showed distinct patterns against the 12 tester wheat lines, A to L. Species or strains whose plasmons showed each fertility spectrum are indicated at the top of the corresponding spectrum. The $y$-axes indicate seed fertility (\%).

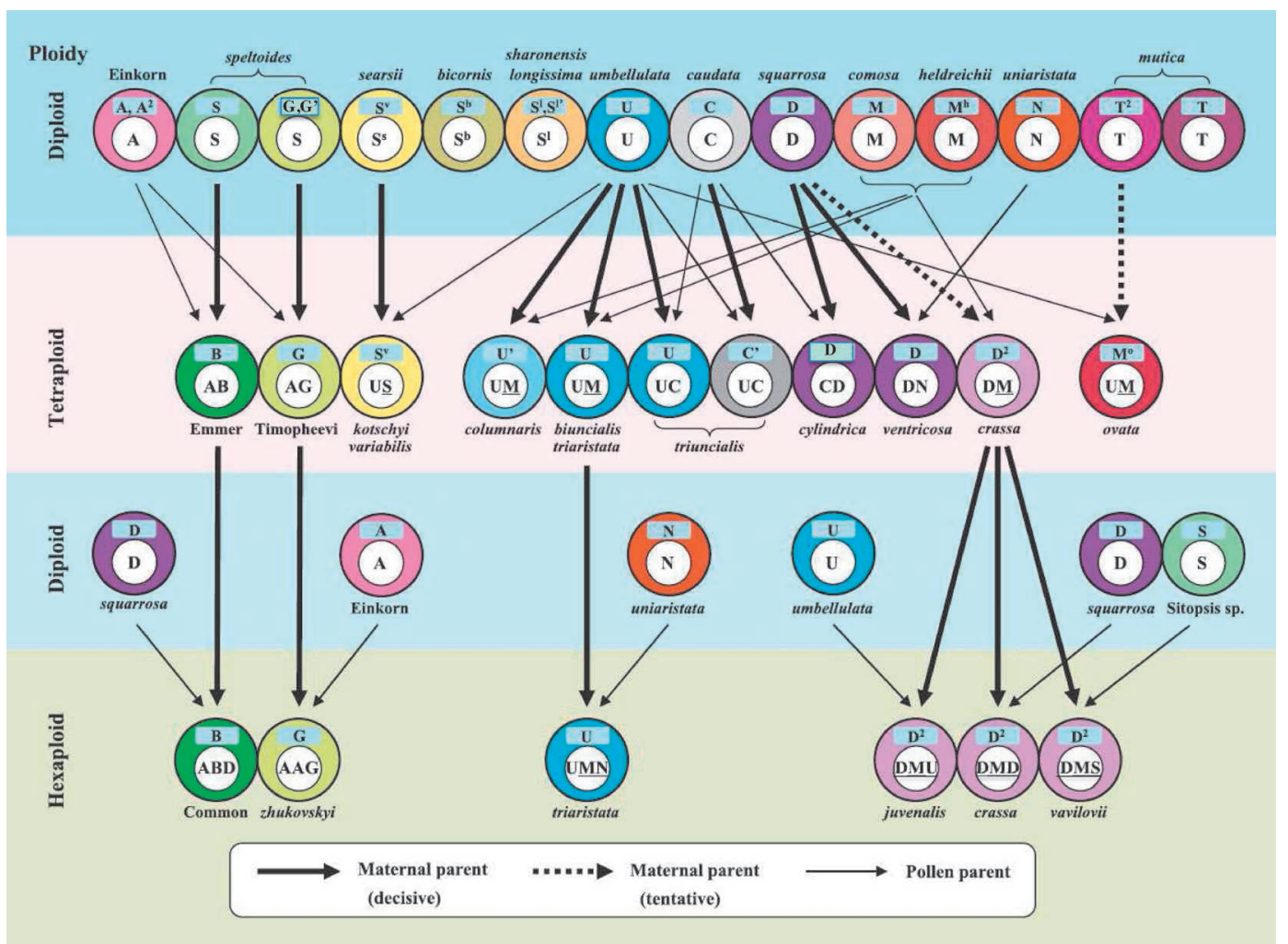

Fig. 7. Phylogenetic relationships between the diploid, tetraploid and hexaploid species of the Triticum-Aegilops complex, based on their genome-plasmon constitution (Tsunewaki 2009, modified). A double circle indicates genome-plasmon constitution of the indicated species, with the inner and outer circles representing haploid genome constitution and plasmon type, respectively. Solid or dashed thick arrows indicate a definitive or tentative maternal lineage, respectively, between the two connected species, whereas thin arrows indicate paternal lineage. Genomes of some polyploid species, which are underlined, are suggested to be modified from the corresponding genomes of their ancestors by Kimber and Sears (1983).

which revealed distinct effects of different groups of plasmon, in terms of the self-pollinated seed fertility spectrum (Fig. 6).
Using the results of performance of all 21 characters, we obtained a matrix of correlation coefficients from sets of 230 standardized 'genotypexcharacter' 
data among 47 plasmons studied. From these results, we recognized that the genetic correlation coefficient of the phenotypic effects between the plasmons, $r=0.85$, was suitable for plasmon type distinction. In addition, we investigated molecular differences in their organellar DNAs by RFLP analyses of chloroplast (ct) and mitochondrial (mt) DNAs (Ogihara and Tsunewaki 1988, Wang et al. 2000). We were also the first group to determine the complete sequences of the ct and $\mathrm{mt}$ genomes of a common wheat, 'Chinese Spring' (Ogihara et al. 2002, 2005). From those results, we found that the genetic distance between the RFLP patterns of mt DNA, $d=0.05$, and the number of ct DNA mutations, $n=1.5$, were also suitable for plasmon type distinction (see Tsunewaki 2009 for review).

Previously, we designated plasmon types for all Triticum and Aegilops species, classifying them to 22 plasmon types (Tsunewaki et al. 2002). Here, we reexamined their plasmon classification applying the above three criteria strictly, and found that four plasmons of Ae. speltoides ligustica (code no. 15), Ae. longissima (code no. 20), Ae. columnaris (code no. 30), and Ae. triuncialis (no. 38), which were classified as plasmon types, $\mathrm{G}, \mathrm{S}^{\mathrm{l}}$, U and $\mathrm{C}$, respectively, were distinctly different from their respective plasmon types. Therefore, we designate them as subtypes of their corresponding plasmon types, and annotate them as the $\mathrm{G}^{\prime}, \mathrm{S}^{1 \prime}, \mathrm{U}^{\prime}$ and $\mathrm{C}^{\prime}$ subtype, respectively.

Based on these plasmon type designations, we could assume the maternal lineages between the diploid and polyploid species as well as those between tetra- and hexaploid species. Combining these results of plasmon analysis with those of genome analysis (Kihara 1949, Kihara and Tanaka 1970), we could determine the maternal relationships (thick lines) and paternal relationships (thin lines) between the species in the TriticumAegilops complex, as shown in Fig. 7.

Our great fortune was that practically all species of the Triticum-Aegilops complex were crossable as females, either directly or indirectly with emmer wheat as a bridging species, which allowed us to breed alloplasmic lines of common wheat with the plasmon of all the more than 30 species of this complex (Table 10) except T. urartu. In conclusion, we were able to establish their phylogenetic relationships, consisting of the maternal and paternal lineages, for the entire Triticum-Aegilops complex, except for a few uncertain cases (dashed arrows in Fig. 7). These are our achievements of the last 100 years, since Sakamura's groundbreaking work, using his materials in part.

\section{Acknowledgements}

In 2010, Dr. E. Shikata, Member of the Japan Academy and Emeritus Professor of Hokkaido University, informed me that Prof. K. Iwama of the College of Agriculture, Hokkaido University (a successor of T. Minami's laboratory) was keeping documents relating to Kihara's wheat stocks, and asked me whether I had any interest in them; I responded positively to his inquiry and soon received from Prof. Iwama a corrugated cardboard box that contained Minami's field notes, carbon copies of his letters and other materials. A search of those materials was the starting point of my work on the origin of T. Sakamura's wheat materials, described in this article; I would therefore like first to express my sincerest appreciation to E. Shikata and K. Iwama. Since then, I obtained important information from M. Yamamoto, staff member of the Archives Section, Main Library, Hokkaido University, particularly about the personal records of T. Minami, T. Sakamura and H. Kihara that are cited here. Dr. Y. Tonomura gifted me a book, "Memoirs of Prof. Tetsu Sakamura", that provided important information about Sakamura's personal contact with the laboratory of Prof. K. Fujii, the founder of Cytologia and the first Professor of the Laboratory of Cytology and Genetics, University of Tokyo. My sincere thanks are due to Dr. N. P. Goncharov, Institute of Cytology and Genetics, Siberian Branch of the Russian Academy of Sciences, for his kindness in providing me a personal English translation of his article (2013) on Flaskberger's life history, which was attached to the article of Flaksberger (1915). Generous help from Dr. S. Ikeguchi, Hokuren Inc., Dr. S. Nasuda, Faculty of Agriculture, Kyoto University and Drs. N. Mori and S. Takumi, both of the College of Agriculture, Kobe University was invaluable in preparation of this article. My deepest appreciation is due to Dr. M. Murata, organizer of the 89th Annual Meeting of the Genetics Society of Japan, and Dr. K. Murai, organizer of the International Symposium on "Celebrating the 100th anniversary of the discovery of correct wheat chromosome numbers and polyploidy by Prof. Tetsu Sakamura" in the above meeting, for allowing me to give a talk on Sakamura's wheat stocks. Finally, I wish to express my cordial thanks to Dr. T. Nagata for his kind consideration to communicate this article to Cytologia and to Dr. Ian Smith for his faithful advice on improvement of the manuscript.

\section{References}

Bally, W. 1912. Chromosomenzahlen bei Triticum und Aegilops Arten. Ein cytologischer Beitrag zum Weizenproblem. Ber. d. D. Bot. Gesellsch. 30: 163-172.

Flaksberger, K. A. 1915. Manual of wheats. Bull. Appl. Bot. 8: 9-210. Goncharov, N. P. 2013. Konstantin Andreevich Flaksberger. Stud. Hist. Biol. 5: 106-108. (in Russian)

Kihara, H. 1924. Cytologische und genetische Studien bei wichtigen Getreidearten mit besonderer Rücksicht auf das Verhalten der Chromosomen und die Sterilität in den Bastarde. Mem. Coll. Sci. Kyoto Imp. Univ. B1: 1-200.

Kihara, H. 1949. Genomanalyze bei Triticum und Aegilops. IX. Systematischer Aufbau der Gattung Aegilops auf genomanalytischer Groudlage. Cytologia 14: 135-144. 
Kihara, H. 1951. Substitution of nucleus and its effects on genome manifestation. Cytologia 61: 177-193.

Kihara, H. 1959. Fertility and morphological variation in the substitution backcrosses of the hybrid between Triticum vulgare $\times$ Aegilops caudata. Proc. X Int. Congr. Genet. 1: 142171.

Kihara, H. 1980. Select Papers of Dr. H. Kihara. Kihara Inst. Biol. Res., Yokohama.

Kihara, H. and Tanaka, M. 1970. Addendum to the classification of the genus Aegilops by means of genome-analysis. Wheat Inform. Serv. 30: 1-2.

Kihara, H. and Wakakuwa, S. 1935. Weitere Untersuchungen über die pentaploiden Triticum-Bastarde. IV. Jpn. J. Bot. 7: 381-387.

Kimber, G. and Sears, E. R. 1983. Assignment of genome symbols in the Triticeae. In: Proc. 6th Int. Wheat Genet. Symp. Kyoto. pp. 1195-1196.

Kimber, G. and Tsunewaki, K. 1988. Genome symbols and plasma types in the wheat group. In: Proc. 7th Int. Wheat Genet. Symp. Cambridge 2: 1209-1210.

Körnicke, M. 1893. Untersuchungen über die Entwicklung der Sexualorgane von Triticum, mit besonderer Berücksichtigung der Kernteilung. Verhandl. Natur. Ver. der Preuss, Rheinl. Westfal. u. Regierungsbez. Osnabrück Jahrg. 53: 149-185.

Lilienfeld, F. A. 1951. H. Kihara: Genome-analysis in Triticum and Aegilops. X. Concluding review. Cytologia 16: 101-123.

Lilienfeld, F. and Kihara, H. 1934. Genome-analysis in Triticum and Aegilops. V. Triticum timopheevi Zhuk. Cytologia 6: 87-122.

Maan, S. S. 1975. Cytoplasmic Variability and Speciation in Triticinae: A Multiple View. Univ. N. D. Press, Grand Forks. pp. 255-281.

Matsumura, S. 1936. Weitere Untersuchungen über die pentaploiden Triticum Bastarde. VII. Beziehung zwischen Chromosomenzahlen und Fruchtbarkeit in den Rückkreuzungen des Bastards $T$. polonicum $\times$ T. Spelta zu den Eltern. Jpn. J. Bot. 8: 205-214.

Matsumura, S. 1940. Weitere Untersuchungen über die pentaploiden Triticum-Bastarde. X. Kreuzungsversuche mit gemischtem pollen. Jpn. J. Bot. 10: 477-487.

Nakao, M. 1911. Cytological studies on the nuclear division of the PMCs of some cereals and their hybrids. J. Coll. Agr. Tohoku Imp. Univ. Sapporo. 4: 173-190.

Navashin, M. 1915. Haploide, diploide und triploide Kerne von Crepis virens Vill. Mem. Soc. Natur. Kiev 25.

Ogihara, Y., Isono, K., Kojima, T., Endo, A., Hanaoka, M., Shiina, T., Terachi, T., Utsugi, S., Murata, M., Mori, N., Takumi, S., Ikeo, K., Gojobori, T., Murai, R., Murai, K., Matsuoka, Y., Ohnishi, Y., Tajiri, H. and Tsunewaki, K. 2002. Structural features of a wheat plastome as revealed by sequencing of chloroplast DNA. Mol. Genet. Genomics 266: 740-746.

Ogihara, Y. and Tsunewaki, K. 1988. Diversity and evolution of chloroplast DNA in Triticum and Aegilops as revealed by restriction fragment analysis. Theor. Appl. Genet. 76: 312-332.

Ogihara, Y., Yamazaki, Y., Murai, K., Kanno, A., Terachi, T., Shiina, T., Miyashita, N., Nasuda, S., Nakamura, C., Mori, N., Takumi, S., Murata, M., Futo, S. and Tsunewaki, K. 2005. Structural dynamics of cereal mitochondrial genomes as revealed by complete nucleotide sequencing of the wheat mitochondrial genome. Nucleic Acids Res. 33: 6235-6250.

Overton, E. 1893. Ueber die Reduktion der Chromosomen in den Kernen der Pflanzen. Vierteljahrs. Naturforsch. Gesellsch. Zürich. p. 38

Panayotov, I. and Gotsov, K. 1976. Interactions between Aegilops cytoplasms and Triticum genomes and evolution of Aegilops. Cereal Res. Commun. 4: 297-306.

Sakamura, T. 1914. Studien über die Kernteilung bei Vicia cracca L. Bot. Mag. 28: 131-147.

Sakamura, T. 1915. Ueber die Einschnürung der Chromosomen bei Vicia fava L. (Vorläufige Mitteilung). Bot. Mag. 29: 287-300.

Sakamura, T. 1916. Über die Beeinflussung der Zell- und Kern-teiliung durch die Chloralisierung mit besonderer Rücksicht auf das Verhalten der Chromosomen. Bot. Mag. 30: 375-399.

Sakamura, T. 1918. Kurze Mitteilung über die Chromosomenzahlen und die Verwandtchafts-verhältnisse der Triticum-Arten. Bot. Mag. 32: 150-153.

Sears, E. R. 1954. The aneuploids of commom wheat. Res. Bull. Mo. Agr. Exp. Stat. 572: 1-59.

Tanaka, M. 1983. Catalogue of Aegilops-Triticum Germ-Plasm Preserved in Kyoto University. Plant Germ-plasm Institute, Faculty of Agriculture, Kyoto University, Kyoto.

Toriyama, H. (ed.) 1982. Memoir of Prof. Tetsu Sakamura. Kaisei Shuppan Co., Tokyo. (in Japanese)

Tsunewaki, K. 1964. Genetic studies of a $6 x$-derivative from an $8 x$ triticale. Can. J. Genet. Cytol. 6: 1-11.

Tsunewaki, K. 2009. Review-Plasmon analysis in the Triticum-Aegilops complex. Breed. Sci. 59: 455-470.

Tsunewaki, K. and Endo, T. R. 1973. Genetic relatedness among five cytoplasms in Triticum and Aegilops. In: Proc. 4th Int. Wheat Genet. Symp., Columbia, MO. pp. 391-397.

Tsunewaki, K., Shimada, T. and Matsuoka, Y. 1999. Transfer of Triticum urartu cytoplasm to emmer wheat is difficult, if not impossible. Wheat Inform. Serv. 88: 27-31.

Tsunewaki, K., Wang, G.-Z. and Matsuoka, Y. 1996. Plasmon analysis of Triticum (wheat) and Aegilops. 1. Production of alloplasmic common wheat and their fertilities. Genes Genet. Syst. 71 293-311.

Tsunewaki, K., Wang, G.-Z. and Matsuoka, Y. 2002. Plasmon analysis of Triticum (wheat) and Aegilops. 2. Characterization and classification of 47 plasmons based on the effects on common wheat phenotype. Genes Genet. Syst. 77: 409-427.

Wang, G.-Z., Matsuoka, Y. and Tsunewaki, K. 2000. Evolutionary features of chondriome divergence in Triticum (wheat) and Aegilops shown by RFLP analysis of mitochondrial DNAs. Theor. Appl. Genet. 100: 221-231.

Wettstein, F. v. 1926. Über plasmatische Vererbung sowie Plasmaund Genwirkung. Nachr. Ges. Wiss. Göttingen Math.-Phys. KI. pp. 250-281.

Wilson, J. A. and Ross, W. M. 1962. Male-sterility interaction of the Triticum aestivum nucleus and Triticum timopheevi cytoplasm. Wheat Inform. Serv. 14: 29-30. 